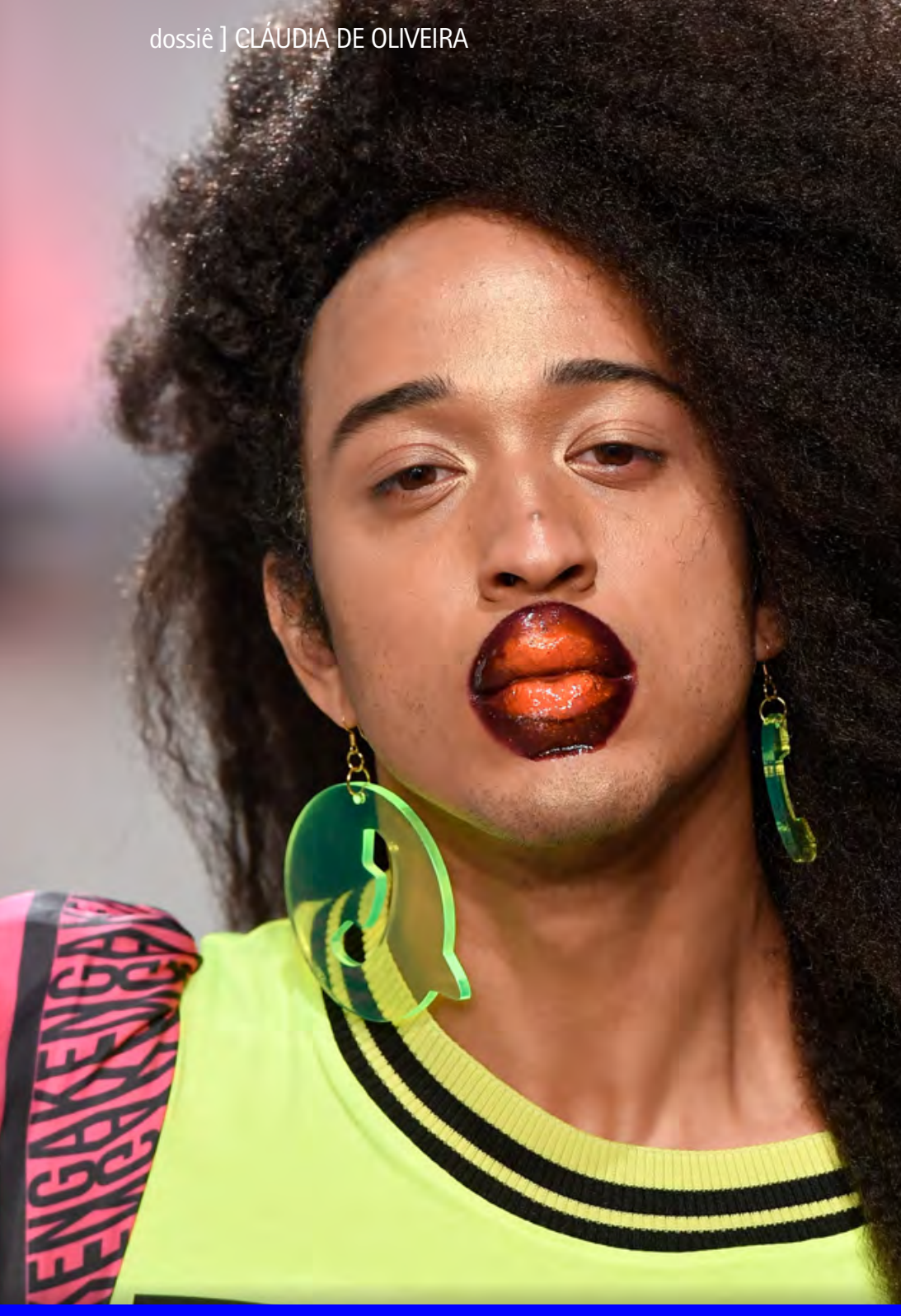

\title{
Mulheres na luta pela emancipação: novo vestuário e novos comportamentos pelas lentes da imprensa carioca - 1900-1914
}

Women in the fight for emancipation: new clothing and new behaviors through the lenses of the Rio de Janeiro press - 1900-1914 


\section{[CLÁUDIA DE OLIVEIRA]}

Doutora em História Social. Professora Adjunta do departamento de História e Crítica de Arte da Escola de Belas Artes da Universidade

Federal do Rio de Janeiro

E-mail: olive.clau@gmail.com

[resumo] Este texto apresenta um estudo de caso que tem como foco o modo como os profissionais da imprensa carioca, homens na sua maioria, representaram novos comportamentos femininos associados a um novo estilo de vestir - ambos adotados por subculturas femininas cariocas compostas por jovens mulheres que começavam a ter acesso à educação e ao mercado de trabalho, no Rio de Janeiro, no começo do século XX. Ao se integrarem ao mundo masculino, essas jovens começaram a usar uma nova indumentária que, progressivamente, passou a incluir itens do guarda-roupa dos homens. Assim, o novo vestuário tornou-se dispositivo político marcador de uma nova posição social para um novo conjunto de mulheres.

[palavras-chave]

vestuário; subculturas femininas; imprensa; Rio de Janeiro.

[abstract] This text presents a case study which focuses on how the predominantly male press in Rio de Janeiro used to present the new female behaviors associated to new dressing styles adopted by Carioca female subcultures. These were comprised of young women who were starting to have access to education and to the labor market in Rio de Janeiro at the beginning of the 20th century. As these youngsters integrated into the male dominated world, they began to wear new outfits that progressively included items from the male wardrobe. Thus, these clothing styles worked as a political instrument to mark a new social position for a new class of women.

[keywords] clothing; female subculture; press; Rio de Janeiro. 


\section{Introdução}

Este texto apresenta um estudo de caso que tem como foco o modo como os profissionais da imprensa carioca, homens na sua maioria, representaram novos comportamentos femininos associados a um novo estilo de vestir - ambos adotados por subculturas femininas cariocas compostas por jovens mulheres que começavam a ter acesso à educação e ao mercado de trabalho, no Rio de Janeiro, no começo do século XX. Ao se integrarem no mundo público masculino, essas jovens começaram a usar uma indumentária que as singularizava, na medida em que introduzia uma diferença no vestuário feminino burguês tradicional, por meio da adoção de itens do guarda-roupa dos homens, como gravatas, colarinhos altos, punhos dobrados, casacos e sapatos abotinados. Assim, elas fizeram do novo vestuário uma arma política que rompia com a mística feminina que, à época, associava a beleza da mulher a uma silhueta cheia e curvilínea, combinada a um vestuário ornamentado e sofisticado, símbolo de um comportamento feminino domesticado e dócil. Nesse contexto, o vestuário adotado por essas novas subculturas femininas tornou-se dispositivo político marcador de uma nova posição social para um novo conjunto de mulheres. Pois, como afirma Daniel Miller (2013), as roupas não representam pessoas, mas constituem-nas, uma vez que o vestuário desempenha papel considerável e atuante na constituição da experiência particular do 97 ] "eu", assim as vestes e as pessoas constituem-se reciprocamente umas às outras (MILLER, 2013, p. 78).

Para tanto, partimos de uma crítica às reflexões feministas pós-estruturalistas (JAGGAR, 1983; BARTKY, 1988) que, apoiadas no conceito "corpos dóceis" de Michel Foucault (2014), na obra Vigiar e punir, entendem os corpos femininos como "dóceis". Ou seja: corpos cujas forças e energias estão habituadas ao controle externo, à sujeição, à transformação por meio de disciplinas rigorosas e reguladoras como a moda, que encarna neste esquema de pensamento uma das disciplinas normativas ou prática cultural-discursiva reguladora e construtora de uma feminilidade resultante das práticas disciplinares impostas pela sociedade heteronormativa'. Muito embora feministas foucaultianas como Margaret McLaren (2016), Donna Haraway (GANE, 2006) e Judith Butler (2015), dentre outras, tenham refletido sobre outras maneiras de se aproximar de Foucault, afirmando que o autor emprega uma concepção de subjetividade corporificada adequada ao feminismo, visto que, para o filósofo, as ligações entre a subjetividade, o institucional e as normas sociais são cruciais para a teoria e a política feminista, essas ligações não ficam claras quando se trata da relação entre as mulheres e as roupas, em que o agenciamento feminino parece sucumbir frente aos padrões impostos pela moda.

É nesta perspectiva que em Body dressing, Joanne Entwistle, socióloga da moda, e a historiadora Elizabeth Wilson insistem em dizer que há 
problemas com o conceito "corpos dóceis" quando este é tomado para uma análise sobre a relação entre a feminilidade e a moda. Primeiramente, a docilização dos corpos é distinta entre homens e mulheres; e, em segundo lugar, como dissemos anteriormente, o conceito não oferece a possibilidade de agenciamento feminino, visto que não possibilita noções de subjetividade e experiência, ao não oferecer uma descrição do vestuário como uma experiência vivida, experimentada e corporificada pelas mulheres (ENTWISTLE; WILSON, 2001, p. 18).

Ainda segundo Entwistle e Wilson (2001, p. 22), os estudos sobre moda desde os anos 2000 têm contemplado cada vez mais os estilos criados pelas subculturas jovens urbanas, os quais muitas vezes se revelam radicais (THORNTON,1995; WILLS, 1990). Este texto toma as premissas de Thornton e Wills para pensar a emergência de subculturas jovens femininas que despontam no início do século XX no Rio de Janeiro e ganham força na década de 1910. Entendemos por subcultura feminina grupos sociais constituídos por mulheres da pequena burguesia ou das classes médias urbanas, que tinham por objetivo o acesso à educação e ao mercado de trabalho na década de 1910. Nossa hipótese é que a representação, pela imprensa carioca do início do século $X X$, dessas subculturas femininas jovens em busca de acesso à educação e ao mercado de trabalho, mostra também como "as construções de gênero se moldam de forma diferenciada no mundo do trabalho e contam com a cumplicidade do vestuário" (FARIAS, 2011, p. 63), evocando, de um lado, uma modernização da aparência feminina, ao mesmo tempo em que tais representações tornam-se elementos demonstradores de reformas sociais.

Por outro lado, não podemos deixar de chamar atenção para o uso da roupa na vida cotidiana, salientando que esse discurso é muito mais complexo e confuso que o discurso da alta-costura, visto que implica uma heterogeneidade nas práticas diárias do vestir, desenhando distinções em termos de classe e status, gênero, idade e afiliações subculturais que, de outra forma, não seriam tão visiveis ou significativas (ENTWISTLE; WILSON, 2001, p. 22). De modo que este estudo, embora entenda que a moda cotidiana se imbrica com a moda criada pela alta-costura, gerando uma circularidade entre ambas, foca especialmente no modo como esses grupos de jovens mulheres se reapropriaram do discurso da alta-costura para os seus novos propósitos - ingressar no mundo público masculino.

Para nossa análise, tomamos quatro revistas ilustradas e cinco jornais que circularam no Rio de Janeiro no início do século XX. As revistas ilustradas eram voltadas para um público de ambos os sexos, majoritariamente pertencente às classes médias e altas, e os jornais eram voltados para 0 grande público. Tal imprensa não era, portanto, especializada em moda, 
mas um meio de comunicação de massa, uma imprensa formadora de opiniões em larga escala. De modo que a segunda hipótese deste trabalho é que o interesse dessa imprensa pela representação das subculturas femininas emergentes assinala outro aspecto extremamente relevante: a valorização de uma cultura jovem feminina, reveladora de outros paradigmas de comportamento. Tal valorização relacionava-se a um contexto de mudanças sociais, econômicas e culturais, próprios à modernidade e à modernização da capital da República, e do Brasil em geral, no início do século XX.

Nesse conjunto de transformações, aqueles grupos de jovens mulheres encarnavam o novo ou a "nova mulher". Como assinala Joviana Fernandes Marques, ao analisar o surgimento da "new women", nos Estados Unidos, no mesmo periodo, "as novas mulheres eram em sua grande maioria muIheres novas" (MARQUES, 2016, p. 20). Assim, a presença desses grupos de jovens mulheres confronta a visão naturalizada da mulher da época, ao revelar uma multiplicidade de grupos femininos que, através do comportamento e de uma nova aparência, subvertiam a noção de passividade feminina imposta pelas normas sociais e também pela moda.

99 ] Ressaltamos também que a fotografia de imprensa da época era uma prática masculina. Por essa razão, acreditamos que a masculinidade deve ser considerada central na produção imagética do fotógrafo de rua, que carregava um conjunto arbitrário de associações culturalmente definidas sobre o corpo, o gênero e o vestuário. Nesse esquema de representação, a feminilidade era servida pelos decotes, saias, cintura marcada/espartilhada e delicadeza dos tecidos; e a masculinidade usava calças, gravatas, tecidos mais pesados, ombros marcados e largos. De modo que os grupos de mulheres analisadas neste texto mostram uma nova expressão da feminilidade que, com seus novos comportamentos e indumentária, embaralha o esquema binário de representação dos gêneros.

As balizas cronológicas, 1900-1914, são demarcadas pelo início da circulação das revistas ilustradas no Rio de Janeiro e pelo fim da Belle Époque, segundo cronologia do historiador Jeffrey Needell (1993) na obra Belle Époque tropical.

\section{Corpos indóceis: novas mulheres, nova indumentária}

No início do século XX ocorrem transformações importantes na hierarquia de gênero no Brasil, especialmente no Rio de Janeiro, visto que muitas mulheres começavam a ter acesso à educação, e outras a entrar no mercado de trabalho. Segundo a historiadora Rosa Araújo, em A vocação do prazer, 
Entre 1890 e 1920, o percentual de mulheres alfabetizadas no Rio de Janeiro cresceu sensivelmente; algumas pioneiras chegaram à educação de nível superior. Muitas cariocas, nos anos finais do século XIX, já trabalhavam, ganhavam seu próprio sustento e estavam livres da dependência econômica masculina, usufruindo de relativa autonomia (ARAÚJO, 1993, p. 45).

Uma parte dessas mulheres passa a engrossar as fileiras do movimento feminista que, embora já fosse o desejo de muitas cidadãs intelectualizadas no século XIX (HUHNER, 1998, p. 98), eclode na primeira década do século XX, especificamente em 1911, com a criação do Partido Republicano Feminino (PRF). Ao estimular o aparecimento coletivo das mulheres na cena política, o feminismo gerou mudanças estruturais importantes (trabalho assalariado, autonomia do indivíduo civil, direito à instrução).

Essas mudanças foram acompanhadas, de um lado, por uma ampla discussão em torno dos direitos da mulher, como a conquista de cidadania plena e o direito ao voto, pauta capitaneada pela subcultura feminista. Por outro lado, uma grande cobertura da imprensa associava em textos, fotografias, caricaturas e anúncios publicitários a emergência da "nova mulher" à modernização da Capital Federal e do país. Contudo, como assinala Margareth Rago, a invasão do cenário urbano pelas muIheres não se traduziu num abrandamento das exigências morais; quanto mais elas escapavam da esfera privada da vida doméstica, tanto mais a sociedade burguesa lançava "sobre seus ombros o anátema do pecado, o sentimento de culpa diante do abandono do lar, dos filhos carentes, do marido extenuado pelas longas horas de trabalho" (RAG0, 1985, p. 62). Ainda assim, fosse por desejo ou por necessidade, muitas foram as mulheres que se lançaram à educação e ao mercado de trabalho nas primeiras décadas do século.

Na fotografia publicada na edição de Fon-Fon! de julho de 1907 (figura 1), vemos um grupo de professoras primárias elegantemente vestidas, caminhando pela Avenida Central. As professoras primárias, na Belle-Époque, correspondiam a mais de dois terços do professorado na Capital Federal, segundo Guacira Louro (1997, p. 445). Observamos na imagem que o fotógrafo apresenta três mulheres jovens que, por serem professoras e atuarem no mundo do trabalho, têm espaço na coluna "Nossos Instantâneos". Contudo, elementos de sua aparência contrastam com a aparência feminina burguesa tradicional no vestir, visto que usam um vestuário marcado por itens próprios à severidade do vestir masculino. 
Figura 1: A severidade nos trajes das jovens professoras remete ao vestuário masculino.

\section{OS NOSSOS INSTANTANEOS}

Um grupo de professoras municipaes

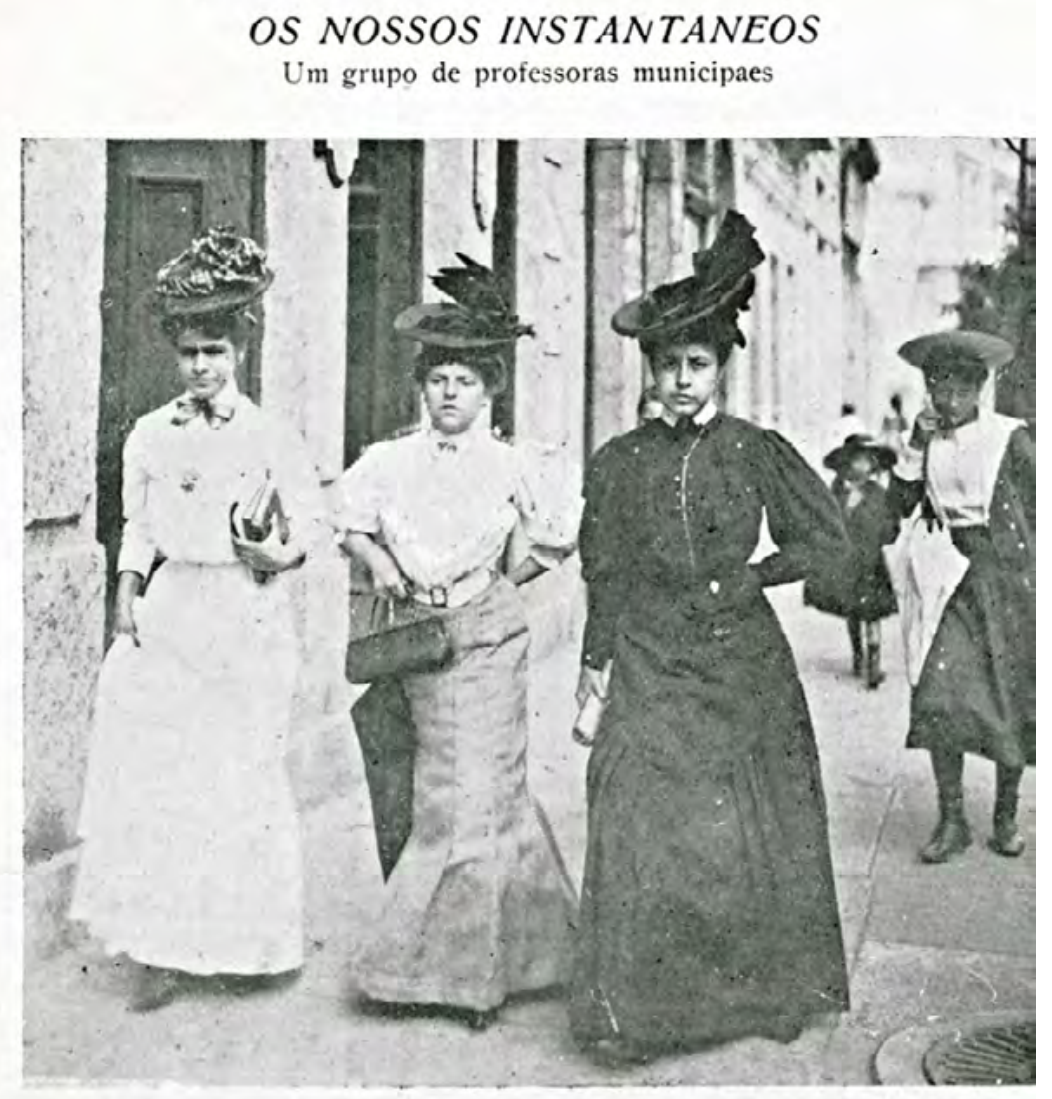

Senhorita Celia Palhares, Mme. Mariana Pinto Porto e Senhorita Antonia Nazareth do Rosario.

Fonte: FON-FON!. Ano 1, n. 26, 27 de julho de 1907. 1 fotografia.

A imagem nos mostra que as jovens usam camisas de mangas largas com punhos dobrados e abotoados; o pescoço e o colo são ocultados por colarinhos altos e dobrados, envoltos em grandes lenços, foulards fechados com broche ou com gravata-borboleta. As três jovens apresentam uma fisionomia severa; a jovem à esquerda carrega livros e a da direita segura rolos de papel - elementos indicadores da mulher profissional. A gravata, 0 foulard, o lenço no pescoço e os punhos dobrados, associados aos livros e aos rolos de papel, convertem-se em elementos indicativos de uma mulher com acesso à educação e ao mercado de trabalho. Assim, a fotografia nos revela três jovens que começam a vestir uma indumentária realçadora de diferenças sexuais, construída a partir do uso de algumas peças masculinas da cintura para cima.

A masculinidade no vestir evoca rigor e severidade, elementos exigidos no mundo do trabalho. Para obter acesso ao mundo masculino, esses 
grupos de jovens mulheres tiveram que negociar com as normas sociais vigentes. Uma dessas negociações se traduziu na construção de uma nova aparência feminina, que associava a feminilidade ao discurso da eficiência e da severidade masculina, entendido como expressão do poder, e que assim desafiava o esquema dualista de gênero das sociedades heteronormativas.

É importante tomarmos o estudo da socióloga da moda Diana Crane sobre o surgimento de uma indumentária feminina alternativa ao estilo feminino burguês nos Estados Unidos, ainda em meados do século XIX, para compreendermos como um novo estilo de vestir começa a se difundir entre aquelas subculturas femininas cariocas. $A$ autora afirma que, a partir do final do século XIX, nos Estados Unidos e Inglaterra, as mulheres provenientes das classes trabalhadoras e médias, para se inserirem no mundo masculino do trabalho, passam a adotar um vestuário considerado por Crane como "não convencional", porque se apropriava de peças do guarda-roupa masculino - como gravatas, chapéus, paletós e camisas (CRANE, 2013, p. 257). Paralelamente, entre meados do século XIX e o ano de 1914, nos Estados Unidos e na Europa, houve um intenso debate em torno de mudanças no vestuário tradicional burguês feminino, proposto por militantes feministas e por médicos e reformadores do vestuário (WILSON, 2003, p. 219). No Brasil, o debate em torno da reforma do vestuário tradicional feminino burguês não reverberou entre as mulheres letradas que lutavam pela emancipação feminina no século $X I X$, já que, por aqui, a pauta dessas mulheres incidiu sobre seu acesso à educação e ao mercado de trabaIho. Nessa pauta, a moda feminina burguesa não foi tratada como um elemento opressor às mulheres, ao contrário do que ocorreu na Europa e nos Estados Unidos.

Por outro lado, tanto as revistas femininas como as feministas, que ocuparam espaço na imprensa a partir de meados do século XIX, deixam de existir no final do século, e são as revistas ilustradas e de entretenimento, que surgem no início do século $X X$, que tomam 0 lugar da imprensa feminina e feminista dos oitocentos. Portanto, foi essa imprensa ilustrada moderna, formada por profissionais masculinos, em sua maioria, que passou a se ocupar das discussões sobre a mulher e a moda feminina no início do século XX. Essa imprensa também não se preocupou em discutir a reforma do vestuário feminino, 0 que assinala a pouca importância da questão no Brasil. De todo modo, no início do século XX no Rio de Janeiro, especialmente a partir da década de 1910, podemos perceber que um novo estilo de vestir vai surgindo entre as subculturas femininas jovens. 
Uma dessas subculturas que começaram a usar a nova indumentária foi a acadêmica. Na fotografia de Fon-Fon! (figura 2) da turma de pintura de Eliseu Visconti, na Academia de Belas Artes em 1910, vemos da esquerda para a direita a estudante Isolina Machado usando uma gravata longa e a quarta jovem, Fedora Rego Monteiro, vestindo um casaco redingote e sapatos abotinados.

Figura 2: Alunas de Belas Artes também adotavam elementos do vestuário masculino.

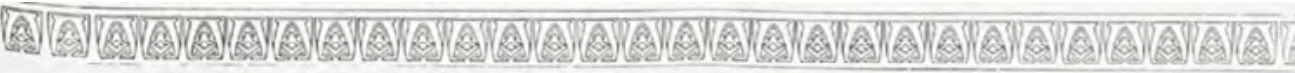

\section{Fon-Fon! na Academia de Bellas Artes}

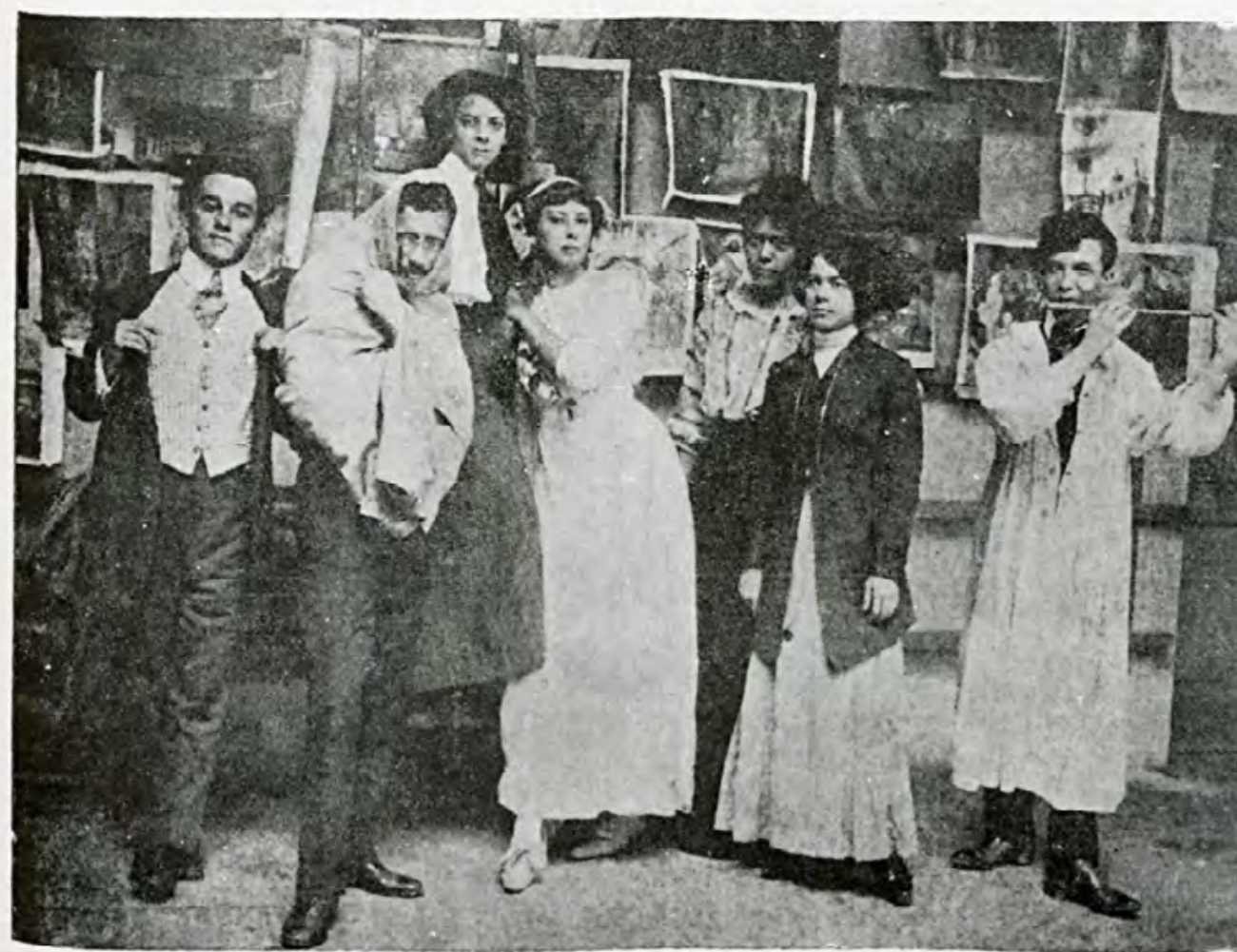

Grupo de discipulos do professor Elyseo Viscont

(da esquerda para a direita) Galdino Bicho, Marques Junior, Isolina Machado, Silvia Meyer, Adelaide Gonçalves, F Fonte: FON-FON!. Ano 4, n. 42, 15 de outubro de 1910. 1 fotografia

Fora do universo acadêmico, vemos pelo anúncio da máquina de escrever Remington, publicado em Fon-Fon! (figura 3) em 1910, uma jovem usando uma gravata longa acompanhada de saia e camisa em tecido risca de giz. Essa imagem nos indica que a gravata também era peça usada pelas jovens que começavam a trabalhar em escritórios, como as datilógrafas. 
Figura 3: Gravata e camisa masculina conferem imagem de eficiência à jovem datilógrafa.

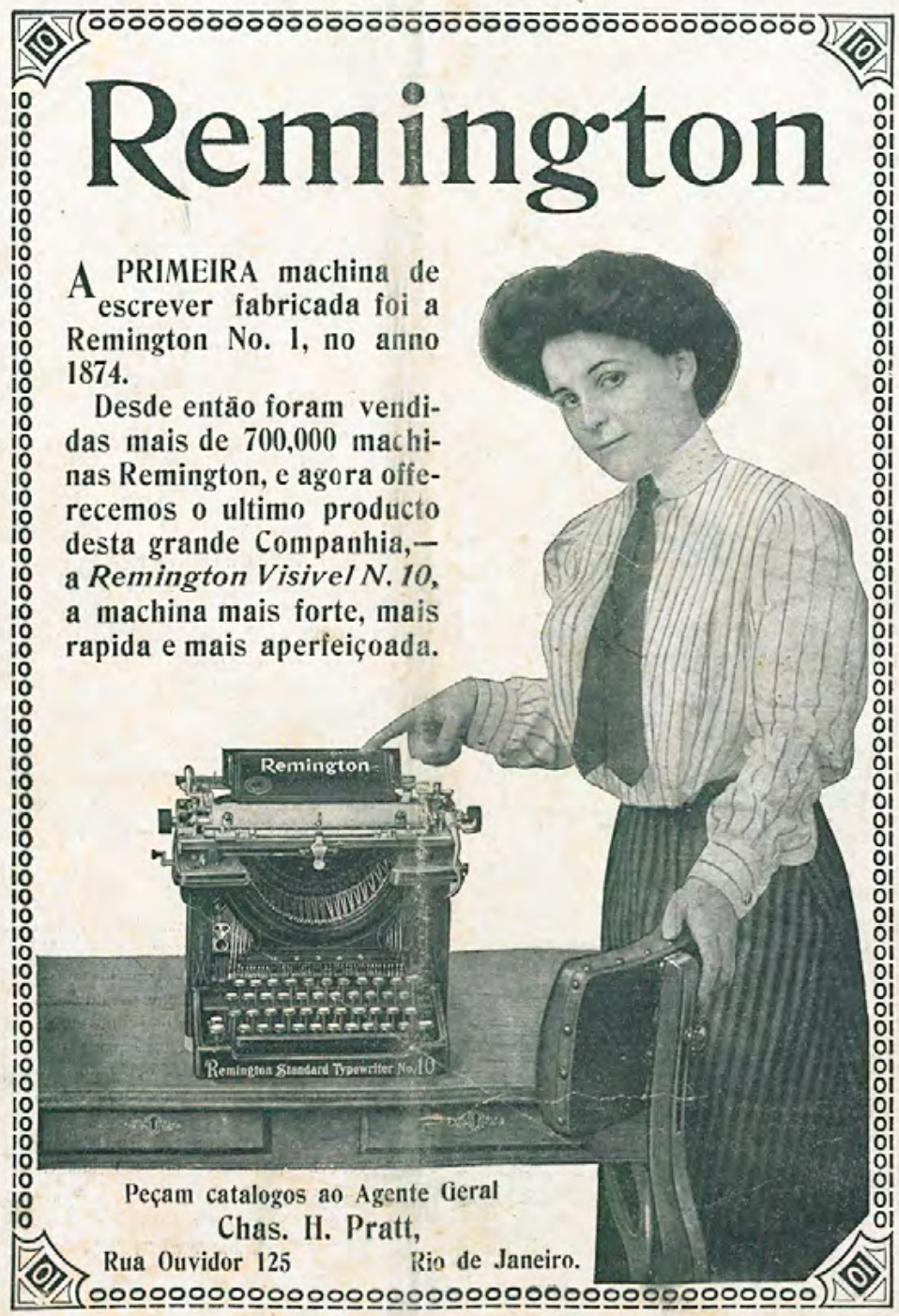

Fonte: FON-FON!. Ano 4, n. 5, 29 de janeiro de 1910. 1 fotografia

Segundo Valerie Mendes e Amy de la Haye (2009), com o aumento de mulheres adentrando o mundo masculino, via educação e trabalho, na Europa e nos Estados Unidos, a alfaiataria torna-se moda entre jovens para os trajes de dia. Assim, a nova indumentária transforma-se "na solução perfeita para as mulheres" (MENDES; LA HAYE, 2009, p. 40).

É importante assinalar nesta discussão a circularidade entre a moda da alta-costura parisiense e a moda cotidiana usada por algumas jovens cariocas nos anos de 1910. Naquela década, o costureiro Paul Poiret, mesmo afirmando nunca ter-se deixado levar pelas discussões dos reformadores do vestuário ou de grupos feministas, já havia provocado o distanciamento 
da silhueta cheia e curvilínea da moda do início da década, rumo a uma linha mais longilínea e esbelta, em criações tubulares e de cintura alta que visavam abolir o espartilho (MENDES; LA HAYE, 2009, p. 52). De modo que, apesar de o corpo cheio ainda continuar na moda, as curvas exageradas foram desaparecendo e o efeito geral do corpo da mulher nos novos trajes era tal qual uma coluna. Essa nova silhueta torna-se ainda mais estreita e esbelta em torno de 1914. Assim, entre 1910 e 1914, muitas mulheres, mesmo as mais liberadas, adotaram a moda da alta-costura criada por Paul Poiret: a saia funil (MENDES; LA HAYE, 2009, p. 52).

Contudo, o importante em nossa análise é que a saia funil auxiliou a construção de uma nova aparência feminina para os grupos de mulheres em luta por emancipação, pois, no novo contexto, as jovens passam a adotá-la como sinônimo de roupa de trabalho. Mesmo não possibilitando movimento e liberdade, a saia funil foi readaptada por esses grupos de jovens, construindo uma aparência feminina que se caracterizava pela simplicidade, o desadorno e o desatavio. Portanto, passa a ser usada como uma peça prática e funcional, de acordo com os novos propósitos dessas jovens, como vemos na imagem "Mariposas do Trabalho" (figura 4), publicada na revista Careta em 1914.

Figura 4: Apesar de criada pela alta costura francesa, a saia funil foi adotada como roupa de trabalho.

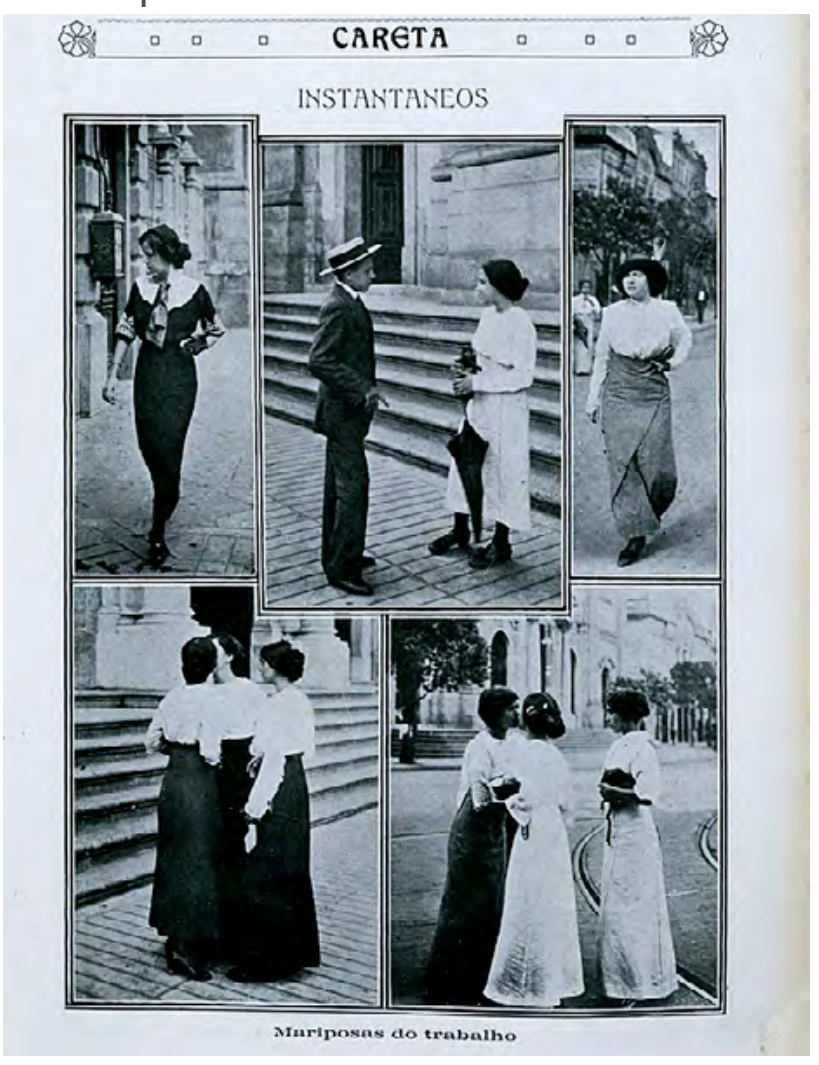

Fonte: CARETA. Ano 7, n. 303, 4 de abril de 1914. 5 fotografias 
0 conjunto de fotos de senhoritas nos chama atenção, primeiramente, pela valorização de mulheres no mundo do trabalho, como indica a legenda original da imagem: "mariposas do trabalho"; e, também, pela valorização de uma subcultura feminina jovem, em oposição à moda das mulheres maduras característica da primeira década do século. Podemos observar que as jovens fotografadas usam trajes que, de um lado estavam dentro do discurso da alta costura - como a saia funil - mas, de outro, ressaltavam a discrição e a adequação à sua nova função social, visto que eram roupas que se destacavam pela combinação de elegância e praticidade, e que, quando usadas com gravata - borboleta ou longa -, tornavam a aparência feminina ainda mais severa. A preferência pelas cores pastel com adornos de cor creme, característica da década anterior (MENDES; LA HAYE, 2009, p. 53), é substituída na década de 1910 pela escolha de cores escuras e tecidos mais pesados - como as saias de sarja e não de musselina. Mesmo as jovens que vestem roupas claras (podendo ser brancas) estão despidas de qualquer ornamento. Eram roupas simples, porém elegantes, práticas, que podiam ser compradas prontas em grandes magazines da Capital Federal. Ou seja, qualquer jovem da pequena ou da média burguesia podia ter acesso a essa indumentária.

O uniforme feminino escolar - novo estilo de vestir para jovens ilustradas

Moças estudantes vestindo uniformes começaram a ser retratadas pelas revistas ilustradas na primeira década do século XX no Brasil. Seu número aumenta a partir da década de 1910, quando ocorre a progressiva abertura de instituições de ensino fundamental para o público feminino (figura 5). Nestas imagens, as jovens são exibidas como símbolo de modernização, pois são apresentadas pela imprensa como jovens mulheres inseridas em instituições de ensino que eram, por sua vez, fruto da modernização social do país.

Figura 5: Moças com uniformes escolares: símbolos de modernização.

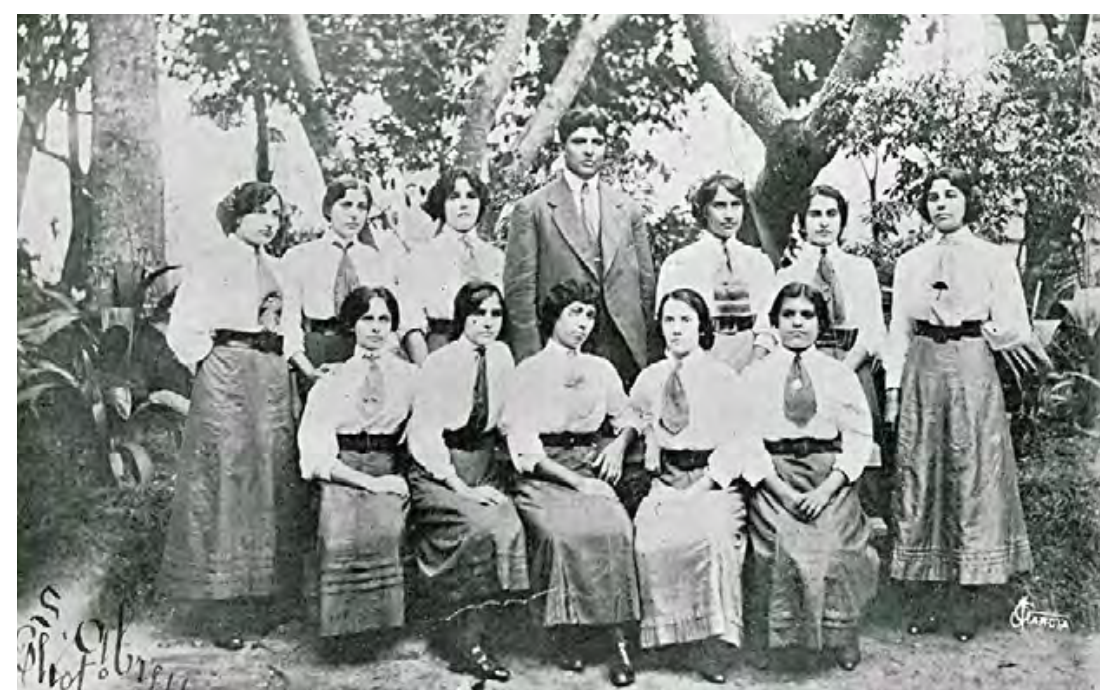

Fonte: FON-FON!. Ano 7, n. 8, 22 de fevereiro de 1913. 1 fotografia 
0 interessante a ressaltar em nossa análise é que a aparência dos uniformes femininos seguia a mesma lógica normativa que a dos uniformes masculinos, ou seja, um traje composto por gravata, camisa de colarinho e o calçado abotinado, acompanhados de elementos da feminilidade, como a saia. Segundo Rita de Cassia Pereira Farias (2011, p. 61), em seu estudo sobre 0 uniforme usado por mulheres nas companhias siderúrgicas e aéreas, o uniforme é um traje que demonstra organização e praticidade, sendo também elemento útil para expressar uma condição oficial de pertencimento a uma instituição, a um grupo ou facção. De modo que o uniforme faz parte de um pacto silencioso de comprometimento, indicando que aquela(e) que o veste assume as normas e a postura ética, neste caso, da instituição escolar.

Se as jovens trabalhadoras cariocas no início do século XX, para adequarem-se ao universo de respeitabilidade masculino, tiveram que negociar sua aparência através da utilização de peças do guarda-roupa do sexo oposto, o que lhes conferia respeitabilidade, em se tratando do uniforme escolar nos parece que o discurso foi o mesmo, visto que a indumentária escolar feminina também assumiu um discurso vestimentar que envolvia uma negociação com a norma vigente, que era masculina. Neste aspecto, o uniforme feminino pode ser lido como uma estratégia disciplinar, que [ IO7 ] denota também o controle corporativo sobre a força de trabalho feminina. Contudo, os uniformes escolares das jovens retratadas nos revelam que elas não só possuiam uma condição oficial de pertencimento a uma instituição, mas também assumiam, assim, as normas, a postura ética e um lugar dentro do universo oficial hierarquicamente masculino.

Neste contexto, a aparência feminina das jovens em uniformes escolares expunha seu acesso a novos conhecimentos, comportamentos, regras e representações (FARIAS, 2011, p. 63). De modo que o uniforme usado por essas jovens se torna, no contexto social da época, um emblema de mudanças sociais representando novos modos de ser, agir e pensar, e encarnando a luta das mulheres por novos espaços sociais. Entendemos, então, que o uniforme usado pelas jovens educandas pode ser lido como afirmação de um novo lugar social feminino, já que o novo traje apresenta um discurso eficiente na luta das mulheres na esfera pública.

Confirmando essas transformações sociais, vemos conjuntos de imagens que nos mostram jovens que haviam obtido diploma superior em profissões reconhecidamente masculinas, como Farmácia, Ciências Contábeis, Odontologia e Medicina. As imagens das jovens doutoras eram associadas, nas revistas, ao feminismo no Brasil, visto, por uma parcela da imprensa, como um canal de ação para o alargamento social para as mulheres. Mas, 0 interessante para nossa análise é que 0 traje adotado pelas jovens era 0 mesmo que o dos homens: a beca ou a toga - um traje que, desde o Império Romano, esteve vinculado ao poder masculino (PEREIRA, 2010, p. 6). 
Se entendemos que o vestir é também uma arte performática ${ }^{2}$, o indivíduo vestido é uma interpretação, visto que as roupas estabilizam a identidade. Sendo a beca ou a toga historicamente uma vestimenta associada ao poder, concluímos que a imagem da mulher vestida de fraque, camisa de colarinho alto e gravata borboleta aponta para uma igualdade entre os sexos, aludindo, dessa maneira, a um rompimento nos códigos binários de gênero e ressaltando um empoderamento feminino dado pela roupa e pelos novos comportamentos, a saber, o acesso à educação.

Assim, podemos considerar que as moças apresentadas nas imagens da imprensa da época usam o vestuário da jovem moderna em busca de um novo lugar social: peças masculinas complementadas com itens da indumentária feminina, construindo, pela aparência, uma nova feminilidade, sintonizada com o seu tempo: a modernidade.

\section{Conclusão}

Figura 6: Sufragistas: o estilo de vestir como ferramenta política.

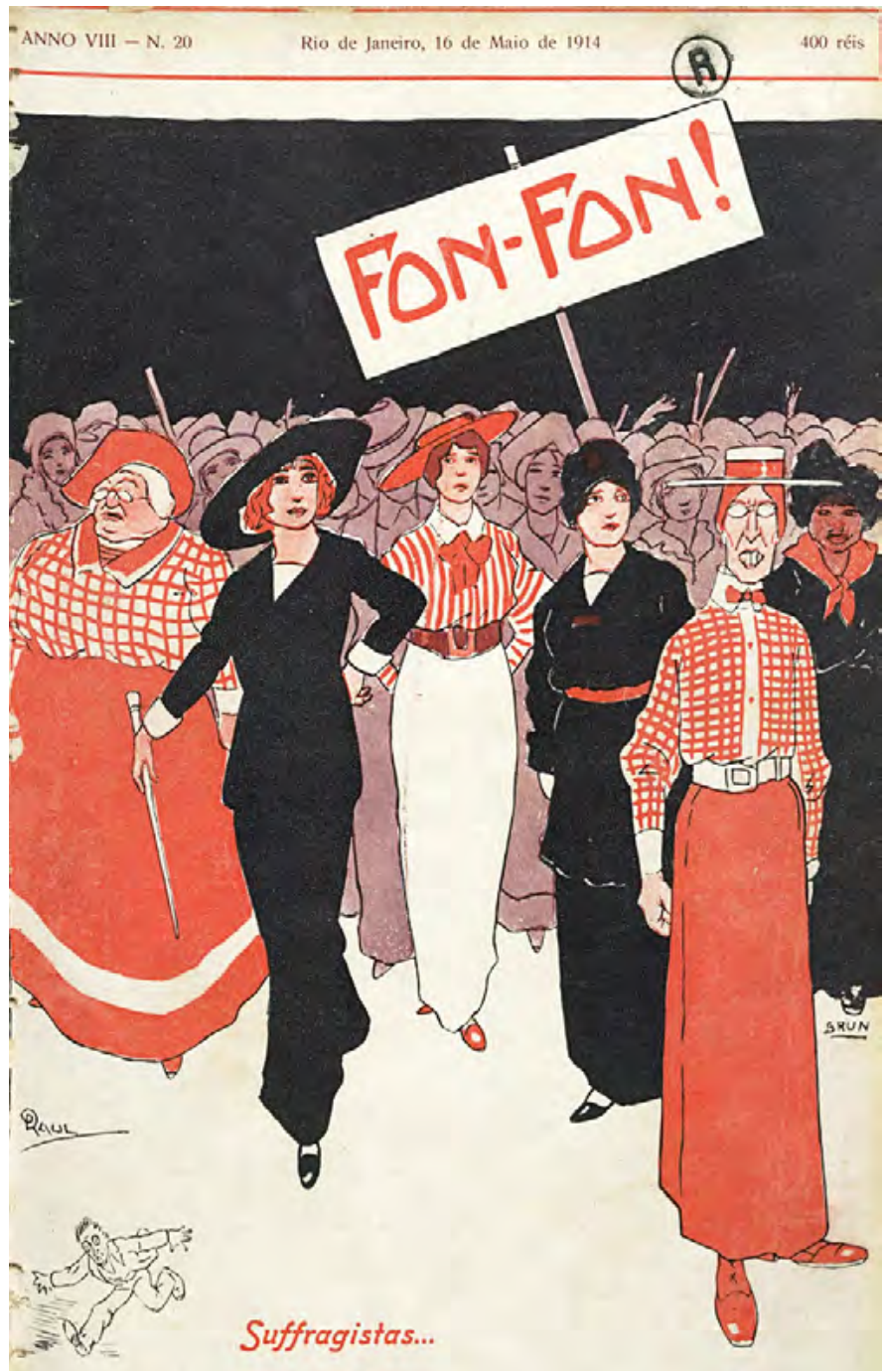

Fonte: FON-FON!. Ano 8, n. 20, 16 de maio de 1914. 1 ilustração 
0 caricaturista Raul Pederneiras registra em caricatura na capa da revista Fon-Fon!(figura 6) as sufragistas do PRF em campanha pelo voto feminino, em 1914. Percebemos na imagem que a moda, além de funcionar como código de distinção nas construções de gênero, identifica estilos de vestir com estilos de comportamento feminino. Tal estilo está associado às "temiveis feministas" que atemorizam o caricaturista, como podemos ver ao lado esquerdo, na parte inferior da imagem. Dessa forma, Pederneiras revela em sua caricatura que os novos grupos de mulheres que adentraram o espaço público, no início do século XX, no Rio de Janeiro, em busca de educação e trabalho, fossem elas feministas ou jovens modernas em luta por um lugar no universo masculino, utilizaram um estilo de vestir que funcionou como afirmação de uma nova identidade feminina, transformando-se em ferramenta política pelas mulheres em seu esforço de avançar na hierarquia social. Mas, mostra-nos também que a imprensa carioca representou a luta entre homens e mulheres no início do século XX não apenas como uma batalha entre os sexos, mas sobretudo como uma forma pela qual essas subculturas femininas experimentaram uma transição de modelos de comportamentos, através de novas expressões da feminilidade, como o estilo de roupa, ao mesmo tempo em que se lançavam à educação e também, profissionalmente, em carreiras masculinas.

Recebido: 29-9-2018

Aprovado: 22-12-2018

\section{NOTAS}

${ }^{1} 0$ conceito heteronormativo é tomado aqui não só no sentido literal da binariedade das práticas sexuais, mas, sobretudo, como uma posição política.

2 Entendemos "arte performática" a partir das reflexões de Judith Butler, que afirma: "atos, gestos e desejo [...] produzem o principio organizador da identidade [...] esses atos, gestos e atuações, entendidos em termos gerais [...] são performativos [...] fabricações manufaturadas (BUTLER, 2015, p. 235). 


\section{REFERÊNCIAS}

ARAÚJO, Rosa Maria B. A vocação do prazer: a cidade e a família no Rio de Janeiro republicano. 2. ed. Rio de Janeiro: Editora Rocco, 1993.

BARTKY, Sandra. Foucault, femininity, and the modernization of patriarchal power. In: DIAMOND, Irene; QUINBY, Lee (ed.). Feminism and Foucault: reflections on resistance. Boston: Northeastern University Press, 1988. p. 63-64.

BUTLER, Judith. Problemas de gênero: feminismo e subversão da identidade. Rio de Janeiro: Civilização Brasileira, 2015.

CRANE, Diana. A moda e seu papel social: classe, gênero e identidade das roupas. São Paulo: Senac, 2013.

ENTWISTLE, Joanne; WILSON, Elizabeth (ed.). Body dressing. Oxford/New York: Berg, 2001.

FARIAS, Rita de Cássia Pereira. Uniforme de trabalho e emancipação feminina. In: BONADIO, Maria Claudia; MATTOS, Maria de Fátima da S. Costa G. História e cultura da moda. São Paulo: Estação das Letras e Cores, 2011. p. 60-84.

FOUCAULT, Michel. Vigiar e punir: nascimento da prisão. Petrópolis: Editora Vozes, 2014.

HUHNER, June E. Emancipação do sexo feminino: a luta pelos direitos da mulher no Brasil: 18501940. Florianópolis: Editora Mulheres, 2003.

JAGGAR, Alison. Feminist politics and human nature. Tottowa, NJ: Rowman and Allanheld, 1983.

LOURO, Guacira. Mulheres em sala de aula. In: DEL PRIORE, Mary; PINSKY, Carla Bassanezi (org.). História das Mulheres no Brasil. São Paulo: Ed Contexto, 1997. p. 443-482.

MCLAREN, Margaret A. Foucault, feminismo e subjetividade. São Paulo: Intermeios, 2016. Coleção Entregêneros.

MARQUES, Joviana Fernandes. Mulheres ilustradas: representações femininas nos Estados Unidos e no Brasil (1890-1945). 2016. Dissertação (Mestrado em Artes, Cultura e Linguagens) - Instituto de Artes e Design, Universidade Federal de Juiz de Fora, Juiz de Fora, 2016.

MENDES, Valerie; LA HAYE, Amy de. A moda do século XX. Rio de Janeiro: Martins Fontes, 2009.

MILLER, Daniel. Trecos, troços e coisas: estudos antropológicos sobre a cultura material. Rio de Janeiro: Editora Zahar, 2013.

NEEDELL, Jeffrey D. Belle Époque tropical: sociedade e cultura de elite no Rio de Janeiro na virada do século. Tradução de Celso Nogueira. São Paulo: Companhia das Letras, 1993.

PEREIRA, Imaculada das Graças Maximiano. A toga e suas significações: dos primórdios à contemporaneidade. Monografia (Especialização em Moda) - Instituto de Artes e Design, Universidade Federal de Juiz de Fora, Juiz de Fora, 2010.

RAGO, Margareth. Do cabaré ao lar: a utopia da sociedade: 1890-1930. Rio de Janeiro: Paz e Terra, 1985.

THORNTON, Sarah. Club cultures: music, media and subcultural capital. Cambridge: Polity Press, 1995.

GANE, Nicholas. When We Have Never Been Human, What Is to Be Done?. Interview with Donna Haraway. Theory, Culture \&t Society, v. 23, n. 7-8, p. 135-158, Dec. 2006. doi:10.1177/0263276406069228

WILLS, Paul. Common culture: symbolic work at play in the everyday cultures of the young. London: Open University Press, 1990.

WILSON, Elizabeth. Adorned In dreams: fashion and modernity. London/New York: I. B. Tauris, 2003. 